\title{
Besides Taste! A Study of Customers' Visual Perception on Service Contact Personnel
}

\author{
Tsui, Pei-ling* \\ Assistant professor, Department of Hospitality Management, National Taitung College, Taiwan \\ *Corresponding Author: Tsui, Pei-ling, Assistant professor, Department of Hospitality Management, \\ National Taitung College, Taiwan
}

\begin{abstract}
:
Background: The recent hospitality industry development has emphasized on service providers' appearances and manners to improve service quality and to provide high quality service experiences. With the growing of customers' aesthetic sense level, service providers have to do basic intimate services, but also to provide sensational high-quality aesthetic experiences to customers. Therefore, this study investigated the influences of service providers' styling, including cosmetics, hair styles, and attires on customers' perception on styling, predicted service quality, predicted service value and satisfaction, based on the Stimulus-Organism-Response theory.
\end{abstract}

Method: This research adopted both qualitative and quantitative approaches in two stages. First, we applied Delphi method to collaborate the knowledge of several experts in related fields, and designed the basic styles of service provides, which are the stimulus in our survey. Next, we surveyed 300 customers of Chinese restaurants of international hotels in Taipei. This study used partial least square path modeling technique to analyze collected data. PLS-PM also known as the variance-based structural equation model is a technique consists of factor analysis, correlation and regression.

Results: The results showed significant influences of service providers' styling on customers' perception, predicted service quality, predicted service value and satisfaction. These results highlighted the importance of a successful service providers styling design.

Originality Value: This study contributed considerably on the concept of service providers' styling in international tourist hotels. By findings of this study can provide hotel human resources management departments for reference, there is a proper guidance and norms in the development of education and training.

Keywords: Makeup; Perception of Styling; Preference of Styling; Service Quality; Chinese Restaurants.

\section{INTRODUCTION}

Restaurant consumers, according to Hyun, Han, \& Kim (2016), take into major concern three factors, including food, environment and attendants. Restaurant managers, therefore, need to understand how satisfied consumers interact with these factors. Consumers' experiences in the three factors and their overall satisfaction can motivate their consumer behavior. Practically speaking, there is no telling whether those who are satisfied with the service quality of a restaurant will have further consumption there. We can be sure, however, that those who do not enjoy the service quality of a restaurant are surely reluctant to pay a second visit. Bearing this in their minds, restaurant managers should elevate service quality, enhance consumer satisfaction and provide marketing strategy to meet the specific needs of the restaurant (Adams \&Doucé, 2017; Dube, Renaghan\& Miller, 1994; Hyun, Han, \& Kim, 2016).

Over the past few years there has been increasing concern about the importance of restaurant attendants' overall styling in the keenly competitive market of food \& drinks (Chen \& Lee, 2018; Mulhern, Fieldman, Hussey, Lévêque, \&Pineau, 2003). Graham and Jouhar (1981) pointed out that consumers tend to have positive evaluation of attendants with makeup styling. They impress others as being healthy and self-confident. Workman and Johnson (1991) presented photos of different models to consumers. Some were with complete makeup, others were with partial makeup, and still others had no makeup at all. Their study showed that makeup styling did make models more appealing to consumers. 
Faced with increasing keen competition, quite a lot of food $\&$ drinks businesses, which emphasize their organizational culture and characteristics, regulate in detail the clothing and makeup styling of their attendants. TGI Friday, McDonald, among others, are good examples. Overall styling is representative of the feature and spirit of a company. It also enables the company to stand out among all market competitors. The overall makeup styling has become one of the most important variables which exert influence on consumer satisfaction. The Taiwanese government has been promoting globalization of Taiwanese cuisine, which is expected to compete with alien cuisines, including Japanese, Korean and Tai food. With "the New Taiwanese Food" being staged internationally, we are sure appropriate overall makeup styling of attendants can better promote Taiwanese cuisine which is characterized by being colorful, fragrant and tasteful. The framework of the present study, which was based on the Stimulus-Organism-Response (S-O-R) proposed by Mehrabian and Russell (1974), endeavored to analyze whether different types of attendants' makeup styling can lead to significant difference on international hotel/restaurant consumers' perception, preference and consumer behavior. Hopefully, this study can not only provide attendants with a new perspective about overall aesthetics but also create grand new international image of the Taiwanese food. The service quality of food \& drinks businesses can be elevated and Taiwan's competitive cutting edge in international tourism can also be enhanced.

\section{LITERATURE REVIEW}

\subsection{S-O-R Model and Consuming Behavior}

Past research based on environmental psychology and the S-O-R model has confirmed that environmental stimulation, consumers' perception and preference, and behavioral intention are significantly correlated. For example, color difference, significantly influences consumers' favor and opinion of a shop (Chen \& Lee, 2018; Mostelleret al., 2014; Tantanatewin \& Inkarojrit, 2018). Consumers are likely to have negative evaluation and perception of a dirty shop or a restaurant and are less satisfied with the service quality (Aksoydan, 2007; Andaleeb, 2001; Babin \& Attaway, 2000; Adams \&Doucé, 2017; Barber \& Scarcelli, 2009, 2010). An Overcrowded shop prevents consumers from further visiting it and reduces consumer satisfaction and pleasure (Eroglu, Machleit, \& Barr, 2005; Hyun, Han, \& Kim, 2016; Larke, Kilgour, \& O'Connor, 2018). Speedy and intensified musical rhythm significantly reduces the amount of time consumers are willing to spend on a shop. This suggests consumers try to withdraw from it (Milliman, 1986). Such a phenomenon is frequently found to occur in eat-to-full restaurants or fast food restaurants which address high turnover rate.

Based on the framework of the S-O-R theory, the present research referred to different types of overall styling as factors of consumer stimulation. The photos of a model with different types of makeup styling were shown to the consumers in the Chinese restaurants of international hotels. The photos of the model, who simulated actual makeup styling of restaurant attendants, were shown to stimulate consumers. Questionnaire survey was implemented to assess respondents' perception and preference of styling, and consumer behavior. Two hypotheses were proposed by the researchers:

H1: Different types of styling exhibited by attendants influence consumers' perception of styling.

H2: Consumers' perception of styling influence consumers' preference of styling.

\subsection{Restaurant Attendants' Makeup Styling and Consumption}

Carpenter and Nakamoto (1989) held the viewpoint that consumers' perception of a specific shop may transform into preference, which again produces brand impression. Market advantage of the shop arises, accordingly. This disables new competitors from completely obliterating the brand of the market forerunner. Oliver and Linda (1981) agreed that consumers' perception and satisfaction surely become deep-rooted product preference and future behavioral intention. By applying the S-O-R theory, Thang and Tan (2003) suggested consumers' preference of a retail store is subject to influence by commodity items, convenience, reputation, offered service and the atmosphere inside the shop, all of which are perceived by consumers.

In an experiment conducted by Cash, Dawson, Davis, Bowen, and Galumbeck (1989), respondents were asked to grade appearance attractiveness of two photos of the same model. The first photo showed the model with full makeup, whereas the other demonstrated the same model without any makeup. The finding indicated that consumers regarded the model with make up as being more attractive and professional. There existed significant difference between the two photos. Guéguen and 
Jacob (2011) and Jacob, Guéguen, Boulbry, and Ardiccioni(2010) found that customers provided positive evaluation of attendants with makeup and were more willing to give a tip. Kim, $\mathrm{Ng}$, and Kim (2009) pointed out attendants' makeup styling was regarded as integral part of the service quality. Therefore, observing consumers' response to and attitude toward different types of makeup styling and understanding the influence caused by their expected service quality can help managers develop their marketing strategy. All literature mentioned above pointed to the fact that the overall styling of attendants can influence consumers' preference of styling through their perception of styling.

No doubt, restaurants which seek for high quality service need to be aware that attractive, professional and appropriate-mannered attendants are determinants of consumers' recurring purchase behavior. When well enhanced, these factors can be applied as an interflow strategy between restaurants and consumers, thus attracting more consumers (Solomon, 2014). In addition, attendants' makeup styling exerts positive influence on consumers' perception of styling and preference of styling. The importance of the influence of attendants' makeup styling on consumer behavior is understandable (Barber, 2008). The present study therefore proposed the following two hypotheses:

H3: Attendants' overall styling influence consumes' preference of styling through consumers' perception of styling.

H4: Consumers' perception of styling and preference of styling influence expected service quality

\subsection{The Image of Restaurant Attendants and Service Quality}

In the early 1970s, there arose the concept that the total environment of a restaurant is significantly related to its service (Kotier, 1973) This concept holds that in addition to product and service, atmosphere and environment also exert influence on consumer experience and purchase decision. Attendants' styling, of course, constitutes part of the actual environment of a shop. Past research indicated that hardware, or so called service environment, is one of the important indices of service quality. Attendants' overall styling is categorized under service environment (Baker, Grewal, \& Parasuraman, 1994).

The design of a restaurant aims mainly to make consumers feel more pleased and satisfied on the hand, and increase employee productivity on the other (Ryu\& Jang, 2008). Granted, the overall styling of attendants is supposed to appeal to customers and raise attendants' performance. Furthermore, keeping clean and tidy is also one of the factors influencing customers' perception of the service quality of a hotel or a restaurant. Therefore, its entrance, external appearance, dining room and suites need to remain clean and tidy all the time (Barber \& Scarcelli, 2010; Lockyer, 2003).

According to O'Neill and Palmer (2001), offering better service quality has become one of the most important strategies whereby service providers can sale themselves. Attendants' overall styling is a key factor of building customers' good impression and brand image (Soloman, 1998). Service quality is regarded to be a factor contributive to customers' recurring purchasing. It is this process that produces customers' preference, establishes brand image and attracts more new consumers (Dubeet al., 1994; Oh, 2000; Yüksel \& Yüksel, 2003). Based on this notion, this study proposed the following three hypotheses:

H5: Consumers' perception of styling and preference of styling influence expected service quality.

H6: Expected service quality influence expected service value.

H7: Expected service quality and expected service value influence customer satisfaction.

\section{Methodology}

\subsection{Research Object}

The present research implemented questionnaire survey. Consumers in high-level Chinese restaurants located in Taipei were targeted as research objects. Purposive sampling was adopted for either inrestaurant customers aged between 20 and 65, or non-in-restaurant potential consumers with consuming experience in Chinese restaurants of international hotels. A total of 300 consumers participated in the survey. After deleting questionnaires with incomplete answers, the researchers obtained 285 valid questionnaires for data analysis. Foreigners and children were not included for their lack of ability to understand the content of the questionnaire or attendants' styling difference. 


\subsection{Research Design}

The researchers showed the photos to the respondents. Photo stimulation generated their feeling about the model's makeup styling. Then, their feeling was converted to their perception of styling, preference of styling and consumer behavior. The control variables of the photo manipulation were two photos showing different types of makeup styling of the model.

In addition, the photo model was a 20 -year-old-average-looking girl. The smiling model was tidily and neatly dressed. She could be seen stooping to serve. Her face makeup styling was highlighted to make it more visible. Two different types of makeup styling were administered to the model by a professional cosmetician. The two photos served as the stimulation factors of the present study.

\subsection{Manipulation of Atmosphere and Plot Design}

Researchers conducted their investigation in international hotels located in Taipei. They looked for, in the restaurant, consumers who were seemingly willing to be surveyed. Upon agreement, the researchers explained the purpose and procedure of the questionnaire survey. The researchers also looked for potential restaurant consumers elsewhere. The researcher orally narrated the scenario to the picked-up participant: "You are now having meal in a high-level restaurant of an international tour hotel. Now that you are properly seated, the attendant will help you as to the meal order and dish description. Tonight, you will be served by this lady (The researcher showed the photo)."

The respondent was shown the photo of the model and then spent some time watching it. According to the S-O-R theory, the respondent was likely to be stimulated by the photo of the attendant. The respondent was asked to answer the questions based on their feeling. The content of the questionnaire included the attendant's makeup styling, consumers' perception and preference, and behavioral intention. The participants' responses to all items and their personal data were then subject to analysis.

The SPSS statistical package was implemented by the researchers for statistical analysis of the returned valid samples. In addition, the researchers used PLS-SEM (partial least squares) to analyze factors, thus verifying the validity of each construct. The researchers also conducted the path analysis of research hypotheses on the basis of the cause-effect relations of all variants which were framed by the conceptual

\section{RESULTS AND DiSCUSSION}

This study referred to two types of makeup styling as stimulation factors, including pink orange and purple blue. The t-test in Table 1 showed the constructs exhibited differences as regards different types of makeup styling. Indeed, restaurant attendants are supposed to be warm and friendly on the one hand and appear professional on the other. Pink orange color system impresses consumers as being warm and friendly, while purple blue color system, which appears gorgeous, may distant attendants from consumers. Pink orange makeup styling, therefore, scored higher.

Table1. The T-test of the Make-up Style

\begin{tabular}{|c|c|c|c|c|c|}
\hline & & Mean & SD. & t & p value \\
\hline \multirow[t]{2}{*}{ Make-up perception } & peach & 3.730 & .921 & \multirow[t]{2}{*}{14.664} & \multirow[t]{2}{*}{$.000 *$} \\
\hline & indigo & 2.235 & .970 & & \\
\hline \multirow[t]{2}{*}{ Preference } & peach & 3.420 & 1.011 & \multirow[t]{2}{*}{8.207} & \multirow[t]{2}{*}{$.000 *$} \\
\hline & indigo & 2.524 & 1.016 & & \\
\hline \multirow[t]{2}{*}{ Expected service quality } & peach & 3.771 & .719 & \multirow[t]{2}{*}{8.141} & \multirow[t]{2}{*}{$.000 *$} \\
\hline & indigo & 3.086 & .840 & & \\
\hline \multirow[t]{2}{*}{ Expected service value } & peach & 3.400 & 1.104 & \multirow[t]{2}{*}{6.405} & \multirow[t]{2}{*}{$.000 *$} \\
\hline & indigo & 2.641 & 1.096 & & \\
\hline \multirow[t]{2}{*}{ Satisfaction } & peach & 3.397 & .985 & \multirow[t]{2}{*}{6.137} & \multirow[t]{2}{*}{$.000 *$} \\
\hline & indigo & 2.738 & 1.012 & & \\
\hline
\end{tabular}

$* \mathrm{p}<.05$

To further confirm the result, the researchers referenced makeup styling as independence variable and perception of makeup styling, preference of makeup styling, expected service quality, expected service value and consumer satisfaction as five dependent variables. They were then subject to multivariate analysis of variance (MANOVA). Table 2 indicated the results of multi-variate analysis of variance. 
Table2. The MANOVA of Make-up Style towards dependent variables

\begin{tabular}{|l|l|c|c|}
\hline & \multicolumn{1}{|c|}{ Dependent Variables } & F & p value \\
\hline Make-up Style & Make-up perception & 217.026 & .000 \\
\cline { 2 - 4 } & Preference & 76.117 & .000 \\
\cline { 2 - 4 } & Expected service quality & 70.612 & .000 \\
\cline { 2 - 4 } & Expected service value & 44.514 & .000 \\
\cline { 2 - 4 } & Satisfaction & 40.509 & .000 \\
\hline
\end{tabular}

$* \mathrm{p}<.05$

We need to be aware that most Chinese restaurants of international hotels do regulate their attendants' hair style and clothing. Facial makeup color and thickness, however, are not strictly regulated. This evidenced managers' ignorance of the importance of attendants' facial makeup.

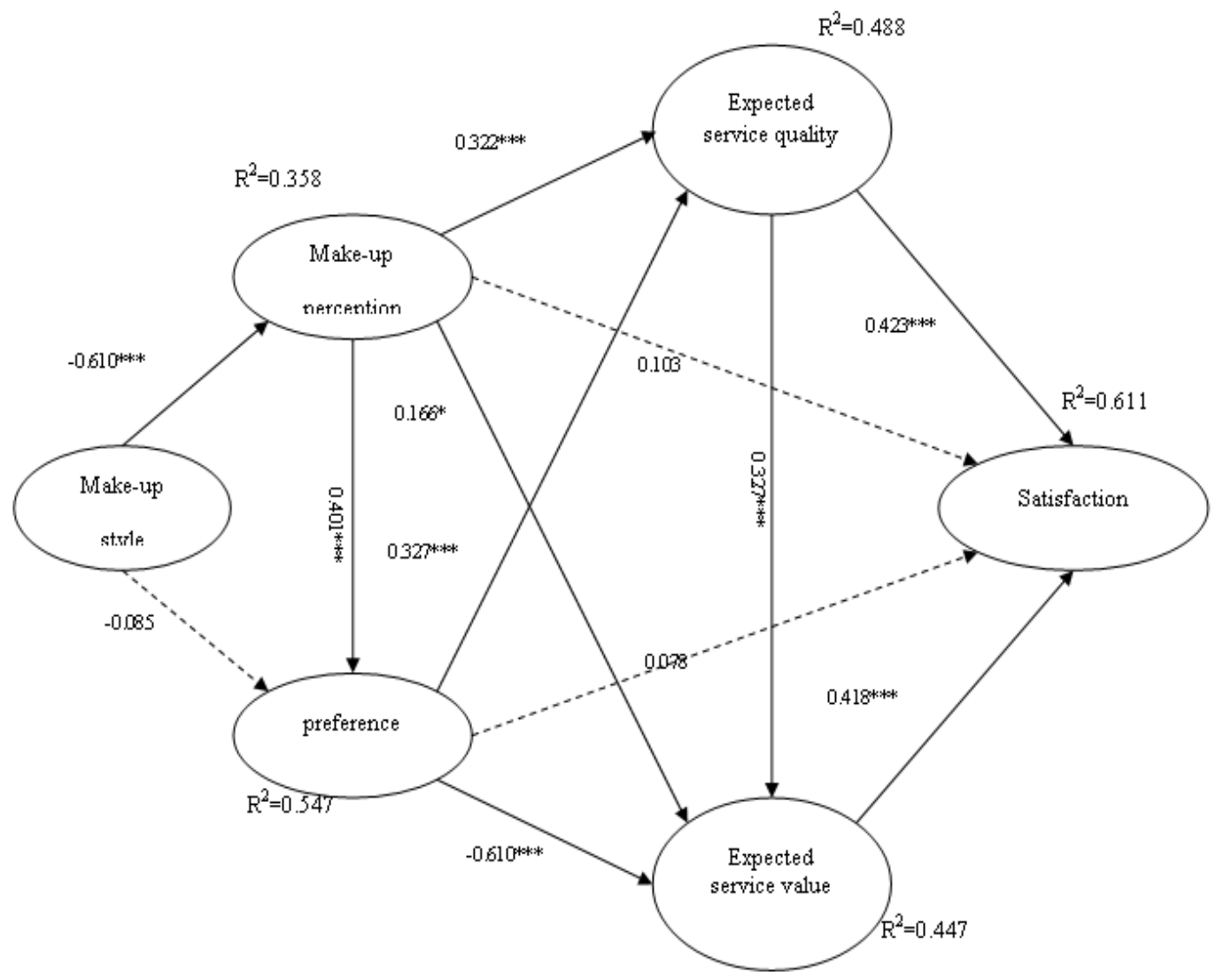

Table3. The result of hypothesis

\begin{tabular}{|l|l|}
\hline \multicolumn{1}{|c|}{ Hypothesis } & \multicolumn{1}{|c|}{$\begin{array}{c}\text { 及(indirect } \\
\text { effect) }\end{array}$} \\
\hline H1: Different types of styling exhibited by attendants influence consumers' perception of styling & $-0.623^{* * *}$ \\
\hline H2: Consumers' perception of styling influence consumers' preference of styling & $0.403^{* * *}$ \\
\hline $\begin{array}{l}\text { H3: Attendants' overall styling influence consumes' preference of styling through consumers' } \\
\text { perception of styling }\end{array}$ & $\begin{array}{l}-0.094(- \\
0.345^{* * *}\end{array}$ \\
\hline H4: Consumers' perception of styling and preference of styling influence expected service quality & \\
\hline H4-1: Consumers' perception of styling influence expected service quality. & $0.331^{* * *}$ \\
\hline H4-2: Consumers' preference of styling influence expected service quality. & $0.324^{* * *}$ \\
\hline $\begin{array}{l}\text { H5: Consumers' perception of styling and preference of styling influence expected service } \\
\text { quality. }\end{array}$ & \\
\hline H5-1: Consumers' perception of styling influence expected service value & $0.156^{* *}$ \\
\hline H5-2: Consumers' preference of styling influence expected service value & $0.213^{* *}$ \\
\hline H6: Expected service quality influence expected service value & $0.323^{* * *}$ \\
\hline H7:Expected service quality and expected service value influence customer satisfaction. & \\
\hline H7-1: Expected service quality influence customer satisfaction & $0.476^{* * *}$ \\
\hline H7-2: Expected service value influence customer satisfaction & $0.429^{* * *}$ \\
\hline
\end{tabular}

$* \mathrm{p}<0.05 、 * * \mathrm{p}<0.01 、 * * * \mathrm{p}<0.001$ 
This study implemented partial least squares (PLS-SEM) to verify hypotheses, which were shown by Figure 1. Concerning Hypothesis One, research analysis demonstrated that stimulation by different styles could effectively influence respondents' perception of styling. The result indicated that makeup styling significantly influenced perception of styling, with $\beta=.623$. The result was supportive of Hypothesis 1.

As regards makeup styling, pink orange color system exerted more influence than purple blue color system. The rationale was that pink orange color system impressed respondents as being easy-going and amiable. Purple blue color system, in contrast, impressed respondents as being too brilliant to offer service.

As to the influence of makeup styling on preference styling, the $\beta$ (coefficient) was found to be 0.403 . This indicated that both makeup styling and perception influenced respondents' reference styling. This conformed to the researchers' inference of Hypothesis 2.

Concerning Hypothesis 3, we assumed that perception of styling could effectively influence respondents' preference of styling through the mediation of perception of styling. Table 3 showed makeup styling did have much mediation effect. Hypothesis 3 was thus accepted.

As to Hypothesis 4 and Hypothesis 5, analysis demonstrated that perception of styling and preference of styling exerted influence on expected service quality and expected service value. Hypothesis 4 and Hypothesis 5 were therefore supported.

Regarding Hypothesis 6 and Hypothesis 7, data analysis showed that service quality and service value did significantly influence consumer satisfaction. This finding completely supported both hypotheses.

\section{CONCLUSION}

This study demonstrated that consumers preferred pink orange color to purple blue color. According to consumers, attendants were not supposed to be heavily made up. On the contrary, they should behave naturally and amiably so as to bring about cozy atmosphere. Restaurants in the past seldom regulated attendants' makeup styling. This study found that different makeup styles did influence consumers' perception. Restaurant managers are advised to take this fact into concern.

Concerning expected attendants' service quality, although the two types of makeup styling scored differently, consumers in the average had relatively high evaluation of both. The two types of makeup styling, which were administered by experts in the related field, were high-level and representative. Consequently, the service quality of the attendant with different types of makeup styling was regarded by consumers as being professional and high-level. This means that attendants' makeup styling transmits a hidden signal to consumers. Consumers are likely to judge the service quality in terms of attendants' makeup styling. The importance of attendants' makeup styling can never be overestimated.

Past research indicated that among different sites, including restaurants, hotels, casinos and malls, consumers' expected service quality and perceived service value directly influence their satisfaction (Dubeet al., 1994; Hu, Kandampully, \&Juwaheer, 2009; Kuo, Wu, \& Deng, 2009; Ryu, Han, \& Kim, 2008; Wong \&Dioko, 2013). The finding of the present study is consistent with previous findings. This means the higher the expected service quality and service value, the more satisfied consumers become. According to this study, appropriate attendants' makeup styling can effectively influence consumers' perception of styling and preference. Higher-level expected service quality and expected service quality will emerge, accordingly. Consumers, as a result, will be satisfied to a greater degree.

Therefore, the finding of this study was similar to those of previous studies. This study proposed a new stimulation factor, namely the overall styling of attendants. The managers of Chinese restaurants in international hotels may refer to this study as a guide to regulating restaurant employees' service portfolio. Thus, they can elevate service quality, increase revenue and build better image.

\section{REFERENCES}

[1] Adams, C., \&Doucé, L. (2017). What's in a scent? Meaning, shape, and sensorial concepts elicited by scents. Journal of Sensory Studies, 32(2), 1-20.

[2] Aksoydan, E. (2007). Hygiene factors influencing customers' choice of dining-out units: Findings from a study of university academic staff. Journal of Food Safety, 27(3), 300-316. 
[3] Andaleeb, S.S. (2001). Service quality perceptions and patient satisfaction: A study of hospitals in a developing country. Social Science \& Medicine, 52(9), 1359-1370.

[4] Babin, B.J. \&Attaway, J.S. (2000). Atmospheric affect as a tool for creating value and gaining share of customer. Journal of Business Research, 49(2), 91-99.

[5] Baker, J. Grewal, D. \&Parasuraman, A. (1994). The influence of store environment on quality inferences and store image, Journal of the Academy of Marketing Science, 22(4), 328-339.

[6] Barber, N.(2008). How Self-confidence and Knowledge Effects the Sources of Information Selected during Purchase Situations, Ph. D Electronic Dissertation (Unpublished), Lubbock: Texas Tech University.

[7] Barber, N. \&Scarcelli, J.M. (2009). Clean restrooms: How important are they to restaurant consumers? Journal of Foodservice, 20(6), 309-320.

[8] Barber, N. \&Scarcelli, J.M. (2010). Enhancing the assessment of tangible service quality through the creation of a cleanliness measurement scale. Managing Service Quality, 20(1), 70-88.

[9] Bitner, M.J. (1990). Evaluating service encounters: The effects of physical surroundings and employee responses. Journal of Marketing, 54(2), 69-82.

[10] Bitner, M.J. (1992). Servicescapes: The impact of physical surroundings on customers and employees. Journal of Marketing, 56(2), 57-71.

[11] Cash, T.F. Dawson, K. Davis, P. Bowen, M. \&Galumbeck, C. (1989).Effects of cosmetics use on the physical attractiveness and body image of American college women. The Journal of Social Psychology, 129(3), 349-355.

[12] Chen, Y. C. D., \& Lee, C. S. (2018). Is it the staff or is it the food? How the attire of restaurant employees affects customer judgments of food quality. British Food Journal. 120 (6), 1223-1235.

[13] Chen, C.F. \& Chen, F.S. (2010). Experience quality, perceived value, satisfaction and behavioral intentions for heritage tourists. Tourism Management, 31(1), 29-35.

[14] Cox, C. \& Glick, W. (1986). Resume evaluations and cosmetics use: When more is not better. Sex Roles, 14(1-2), 51-58.

[15] Dube, L. Renaghan, L.M. \& Miller, J.M. (1994). Measuring customer satisfaction for strategic management. Cornell Hotel and Restaurant Administration Quarterly, 35(1), 39-47.

[16] Eroglu, S.A. Machleit, K. \& Barr, T.F.(2005). Perceived retail crowding and shopping satisfaction: The role of shopping values. Journal of Business Research,58(8), 1146-1153.

[17] Gounaris, S. Dimitriadis, S. \&Stathakopoulos, V. (2010). An examination of the effects of service quality and satisfaction on customers' behavioral intentions in e-shopping. Journal of Services Marketing, 24(2), 142-156.

[18] Graham, J.A. \&Jouhar, A.J. (1981). The effects of cosmetics on person perception. International Journal of Cosmetic Science, 3(5), 199-210.

[19] Guéguen, N. \& Jacob, C. (2011). Enhanced female attractiveness with use of cosmetics and male tipping behavior in restaurants. Journal of the Society of Cosmetic Chemists, 62(3), 283-290.

[20] Harrell, G.D. Hutt, M.D. \& Anderson, J.C. (1980). Path analysis of buyer behavior under conditions of crowding. Journal of Marketing Research, 17(1), 45-51.

[21] Hu, H.H. Kandampully, J. \&Juwaheer, T.D. (2009). Relationships and impacts of service quality, perceived value, customer satisfaction, and image: An empirical study. The Service Industries Journal, 29(2), 111-125.

[22] Hyun, SS., Han, H., \& Kim, W. (2016). A Model of Patrons' Impulsive Ordering Behaviors in Luxury Restaurants. Asia Pacific Journal of Tourism Research, 21(5), 541-569.

[23] Jacob, C. Guéguen, N. Boulbry, G. \&Ardiccioni, R. (2010). Waitresses' facial cosmetics and tipping: A field experiment. International Journal of Hospitality Management,29(1), 188-190.

[24] Kim, W.G. Ng, C.Y.N. \& Kim, Y.S. (2009). Influence of institutional dineserv on customer satisfaction, return intention, and word-of-mouth. International Journal of Hospitality Management,28(1), 10-17.

[25] Kotier, P. 1973. 'Atmospherics as a marketing tool', Journal of Retailing, 49(1): 48-64.

[26] Kuo, Y.F. Wu, C.M. \& Deng, W.J. (2009). The relationships among service quality, perceived value, customer satisfaction, and post-purchase intention in mobile value-added services. Computers in Human Behavior, 25(4), 887-896.

[27] Larke, R.,Kilgour, M., \& O’Connor, H. (2018). Build touchpoints and they will come: transitioning to omnichannel retailing. International Journal of Physical Distribution \& Logistics Management, 48(4), 465-483.

[28] Lockyer, T. (2003). Hotel cleanliness-how do guests view it? Let us get specific. A New Zealand study. International Journal of Hospitality Management, 22(3), 297-305. 
[29] Mehrabian, A. Russell, J.A. (1974). An approach to environmental psychology. Cambridge, MA: The MIT Press.

[30] Mosteller, J., Donthu, N., \&Eroglu, S. (2014). The fluent online shopping experience. Journal of Business Research, 67(11), 2486-2493.

[31] Milliman, R.E. (1986). The influence of background music on the behavior of restaurant patrons. Journal of Consumer Research, 13(2), 286-289.

[32] Mulhern, R. Fieldman, G. Hussey, T. Lévêque, J.L. \&Pineau, P.(2003). Do cosmetics enhance female Caucasian facial attractiveness? International Journal of Cosmetic Science, 25(4), 199-205.

[33] O’Neill, M. \& Palmer, A. (2001). Survey timing and consumer perceptions of service quality: An overview of empirical evidence. Managing Service Quality, 11(3), 182-190.

[34] Oh, H. (2000). Diners' perceptions of quality, value, and satisfaction: A practical viewpoint. Cornell Hotel and Restaurant Administration Quarterly, 41(3), 58-66.

[35] Oliver, R.L. Linda, G. (1981). Effect of satisfaction and its antecedents on consumer preference and intention. Advances in Consumer Research, 8(1), 88-93.

[36] Parasuraman, A. Zeithaml, V.A. \& Berry, L.L. (1988). Servqual: A multiple-item scale for measuring customer perceptions of service quality. Journal of Retailing, 64(1), 12-40.

[37] Ryu, K. Jang, S. (2008). Dinescape: A scale for customers' perception of dining environments. Journal of Foodservice Business Research, 11(1), 2-22.

[38] Ryu, K. Han, H. \& Kim, T.H. (2008). The relationships among overall quick-casual restaurant image, perceived value, customer satisfaction, and behavioral intentions. International Journal of Hospitality Management,27(3), 459-469.

[39] Soloman, M.R. (1998). Dressing for the part: The role of costume in the staging of the servicescape. In Sherry, J.F. (Ed.). Servicescapes: The concept of place in contemporary markets. Chicago: American Marketing Association.

[40] Solomon, M. R. (2014). Consumer behavior: Buying, having, and being. Prentice Hall Engelwood Cliffs, NJ. Retrieved from http://www.academia.edu/download/38962867/Consumer-Behavior.pdf

[41] Stevens, P. Knutson, B. \& Patton, M. (1995). Dineserv: A tool for measuring service quality in restaurants. Cornell Hotel and Restaurant Administration Quarterly, 36(2), 56-60.

[42] Tantanatewin, W., \& Inkarojrit, V. (2018). The influence of emotional response to interior color on restaurant entry decision. International Journal of Hospitality Management, 69, 124-131.

[43] Wong, I.A. \&Dioko, L.N. (2013). Understanding the mediated moderating role of customer expectations in the customer satisfaction model: The case of casinos. Tourism Management, 36, 188-199.

[44] Workman, J.E. \& Johnson, K.K.P. (1991). The role of cosmetics in impression formation. Clothing and Textiles Research Journal,10(1), 63-67.

[45] Yüksel, A. \&Yüksel, F. (2003). Measurement of tourist satisfaction with restaurant services: A segmentbased approach. Journal of Vacation Marketing, 9(1), 52-68.

Citation: Tsui, Pei-ling. "Besides Taste! A Study of Customers' Visual Perception on Service Contact Personnel". International Journal of Research in Tourism and Hospitality (IJRTH), vol 5, no. 1, 2019, pp. 815. doi: http://dx.doi.org/10.20431/2455-0043.0501002.

Copyright: (c) 2019 Authors. This is an open-access article distributed under the terms of the Creative Commons Attribution License, which permits unrestricted use, distribution, and reproduction in any medium, provided the original author and source are credited. 